\title{
Validity and Reliability of the Persian Version of Baecke Habitual Physical Activity Questionnaire in Healthy Subjects
}

\author{
Meissam Sadeghisani, ${ }^{1,}$ Farideh Dehghan Manshadi, ${ }^{1}$ Hadi Azimi, ${ }^{2}$ and Ali Montazeri ${ }^{3}$ \\ ${ }^{1}$ Department of Physiotherapy, School of Rehabilitation Sciences, Beheshti University of Medical Sciences, Tehran, IR Iran \\ ${ }^{2}$ Department of English Language Teaching, School of Medicine, Shahid Beheshti University of Medical Sciences, Tehran, IR Iran \\ ${ }^{3}$ Department of Mental Health, Iranian Institute for Health Sciences Research, Tehran, IR Iran \\ "Corresponding author: Meissam Sadeghisani, Department of Physiotherapy, School of Rehabilitation Sciences, Shahid Beheshti University of Medical Sciences, Tehran, IR Iran. \\ Tel: +98-3833332487; +98-9137716567, E-mail: sadeghi.m@sbmu.ac.ir
}

Received 2015 July 24; Revised 2015 October 23; Accepted 2015 December 10.

\begin{abstract}
Background: Baecke Habitual Physical Activity Questionnaire (BHPAQ) has widely been employed in clinical and laboratorial studies as a tool for measuring subjects' physical activities. But, the reliability and validity of this questionnaire have not been investigated among Persian speakers.

Objectives: Therefore, the aim of the current study was examining the reliability and validity of the Persian version of the BHPAQ in healthy Persian adults.

Materials and Methods: After following the process of forward-backward translation, 32 subjects were invited to fill out the Persian version of the questionnaire in two independent sessions (3 - 7 days after the first session) in order to determine the reliability index. Also, the validity of the questionnaire was assessed through concurrent validity by 126 subjects ( 66 males and 60 females) answering both the Baecke and the International Physical Activity Questionnaire (IPAQ).

Results: An acceptable level of intraclass correlation coefficient $($ ICC of work score $=0.95$, sport score $=0.93$, and leisure score $=0.77$ ) was achieved for the Persian Baecke questionnaire. Correlations between Persian Baecke and IPAQ with and without the score for sitting position were found to be 0.19 and 0.36 , respectively.

Conclusions: The Persian version of the BHPAQ is a reliable and valid instrument that can be used to measure the level of habitual functional activities in Persian-speaking subjects.
\end{abstract}

Keywords: Validity, Reliability, Baecke Questionnaire, Persian Version

\section{Background}

Physical activity is an important modifying risk factor for preventing primary and secondary causes of disability and even death (1). Recent evidence has revealed that physical activity is beneficial in the management of primary risk factors in many diseases including diabetes and cardiovascular conditions $(2,3)$. In addition, promotion of the level of physical activity has shown to have positive results in the prevention of secondary risk factors of cancer, osteoporosis, and musculoskeletal diseases $(1,4,5)$. As a result, it seems that evaluation and measurement of the functional status and the level of physical activities are central goals to pursue in epidemiological studies, and especially in health care fields (6).

In rehabilitation sciences, measurement of the level of physical activities is performed to evaluate patients' functional status before and after a certain treatment in order to determine how efficient a health care program has been for the patients (7).
Epidemiological studies investigate the relationship between level of physical activities, health status, and psychological aspects. Therefore, measurement of functional and physical activities is also an important goal in rehabilitation clinics and epidemiological studies.

Two methods are used to measure physical activities: direct and indirect (8). For direct measurement of physical performance, in addition to the specific methods and tests that are required, for instance $\mathrm{VO}_{2 \max }$, food uptake, and heart rate, subjects must perform a specific task. Indirect methods, on the other hand, employ data collection procedures such as subjects filling out self-reporting questionnaires $(7,9,10)$.

In comparison to the direct methods, indirect measurements of physical activities, carried out via instruments such as questionnaires, are inexpensive, easy to access, timesaving, and can be used effectively in the studies that require data collection from a large number of subjects $(7,11)$. 
During self-reporting measures, the subject's level of physical status is determined based on the score the individual obtains by answering the items in the questionnaire. In other words, a subject's functional physical activities prior to and after a treatment can be compared using the scores he/she obtains before and after the treatment.

Currently, there are many self-reporting questionnaires that can be employed for measuring the level of physical activities (12-16). One of the useful self-reporting instruments that is widely used in assessing physical performance of different groups is Baecke habitual physical activities questionnaire.

One advantage of this questionnaire, in comparison to the other self-reporting questionnaires, is that it includes a broad range of the subjects' physical activities during work, sport, and recreational occasions (13). Moreover, this questionnaire covers a long period of the individuals' physical activities in the past (13).

Moreover, Baecke habitual physical activity questionnaire is widely known and extensively used in clinical and laboratorial studies of musculoskeletal disorders for measuring the subjects' level of physical activities (17-19).

Additionally, this questionnaire has already been employed in different studies and for different patients, such as patients of HIV, cardiovascular disorders, obesity, etc. (20-25). Validity and reliability of Baecke questionnaire in physical activities measurement are assessed in both healthy and ill subjects $(10,13,21,26,27)$. Furthermore, the validity and reliability of Baecke questionnaire are examined and reported in different languages $(10,13,21,26,27)$.

Despite the fact that, currently, numerous selfreporting instruments for physical activities measurement are being employed in Iran $(7,28,29)$, no Persian version of these questionnaires are available that includes the subjects' broad physical activities in a long period of time to be used for different healthy and ill populations. The Baecke questionnaire, however, is a useful instrument which can assess a person's long period of physical activities (the previous year) and can be used for both healthy and ill people. However, the reliability and validity of this questionnaire have not been studied in the previous investigations.

\section{Objectives}

The aims of the present study were to translate Baecke habitual physical activity questionnaire into Persian and also to examine the reliability and validity of the new version in healthy adult subjects who are native speakers of Persian.

\section{Materials and Methods}

\subsection{Habitual Physical Activity Questionnaire}

The Baecke questionnaire is a tool that evaluates individual's habitual physical activities over the previous 12 months. This questionnaire consists of 16 questions within three main domains of individual physical activities (occupational, sport, and recreational), in the previous 12 months (13). Measurement of individual physical activities is achieved by calculating the sum of the scores obtained from occupational, sport, and recreational categories.

\subsection{Translation Process}

Initially, based on the standardized cross-cultural translation guidelines project (30), the English version of the Baecke questionnaire was translated into Persian. The translation was done by two independent translators, who were native Persian speakers and were not previously familiar with Baecke questionnaire. Next, in a joint meeting, both translators worked and agreed on a common translation. Then, the questionnaire was back translated from Persian to English by two professional translators. The translators and researchers both checked and agreed on the final Persian version. Afterward, the new questionnaire was used to conduct a pilot study on 20 healthy subjects in order to determine the content validity of the questionnaire (7).

\subsection{Participants}

Subjects were young men and women, aged between 20 - 40 years, who lived in Shahrekord, Iran. All the participants were Persian native speakers who were able to speak and write fluently in Persian. The subjects were selected based on convenience sampling. In total, 66 males and 60 females participated in the present study. All the participants were healthy people with no signs and symptoms of neurological, orthopedic, psychological, metabolic, and immunological illnesses during the previous year. Subjects were excluded from the study if they were illiterate, were not native speakers of Persian, and had a recent disease. Also, participation in the study was voluntary for the subjects. Demographic characteristics of the subjects are presented in Table 1 . The following equation was utilized to determine the sample size for the study.

$$
\begin{aligned}
& N=\left\{\frac{z_{1-\frac{\alpha}{2}}+z_{1-\beta}}{\frac{1}{2} \ln \frac{1+r}{1-r}}\right\}+3 \\
& \mathrm{Z}_{1-\alpha / 2}=1.96 ; \mathrm{Z}_{1-\beta}=1.28 \text {. } \\
& \alpha=0.05 ; \beta=0.1 \text { (power }=0.9 \text { ), } \mathrm{r}=0.3 \text { (moderate effect } \\
& \text { size), } \mathrm{N} \sim 118 \text {. }
\end{aligned}
$$


Table 1. Characteristics of the Participants ${ }^{\mathrm{a}}$

\begin{tabular}{|c|c|c|c|c|}
\hline Parameter & Males $(N=66)$ & Females $(N=60)$ & Mean Differences & PValue \\
\hline Age, $y$ & $25.16 \pm 4.9$ & $25.9 \pm 5.8$ & -0.76 & 0.42 \\
\hline Weight, kg & $69.31 \pm 10.4$ & $58.53 \pm 8.3$ & 10.7 & $0.00^{\mathrm{b}}$ \\
\hline Height, m & $1.74 \pm 0.07$ & $1.63 \pm 0.05$ & 10.5 & $0.00^{\mathrm{b}}$ \\
\hline BMI, $\mathrm{kg} / \mathrm{m}^{2}$ & $22.7 \pm 2.9$ & $21.8 \pm 2.9$ & 0.95 & 0.07 \\
\hline \multicolumn{5}{|l|}{ Baecke score } \\
\hline Work score & $2.7 \pm 0.7$ & $2.9 \pm 0.5$ & -0.19 & 0.08 \\
\hline Sport score & $2.7 \pm 1.2$ & $2.3 \pm 1.1$ & 0.43 & $0.04^{\mathrm{b}}$ \\
\hline Leisure score & $2.5 \pm 0.5$ & $2.5 \pm 0.7$ & 0.43 & 0.9 \\
\hline Total score & $8.1 \pm 1.5$ & $7.8 \pm 1.6$ & 0.25 & 0.38 \\
\hline \multicolumn{5}{|l|}{ IPAQ score } \\
\hline Work score & $232.8 \pm 176$ & $288.9 \pm 328.7$ & -56.0 & 0.22 \\
\hline Transport score & $383.6 \pm 243.9$ & $394.5 \pm 389.5$ & -10.8 & 0.85 \\
\hline Home/garden score & $144.2 \pm 197.6$ & $202.9 \pm 205.7$ & -58.6 & 0.1 \\
\hline Leisure score & $174.2 \pm 155.8$ & $153.2 \pm 179.2$ & 20.9 & 0.48 \\
\hline Siting score & $400.8 \pm 273.9$ & $537.7 \pm 951.4$ & -136.9 & 0.26 \\
\hline Total score without siting score & $935 \pm 399.6$ & $1039.6 \pm 687$ & -104.6 & 0.29 \\
\hline Total score with siting score & $1335.8 \pm 487.4$ & $1577.4 \pm 1159.8$ & -241.5 & 0.12 \\
\hline
\end{tabular}

Abbreviations: SD, standard deviation; IPAQ, international physical activity questionnaire; BMI, body mass in mean \pm SD

${ }^{\mathrm{a}}$ Values are expressed as mean $\pm \mathrm{SD}$.

${ }^{\mathrm{b}}$ Significant P value.

\subsection{Construct Validity Assessment}

For the purpose of validation, the Persian version of the Baecke questionnaire was administered to 126 healthy subjects. Each subject received a copy of international physical activity questionnaire IPAQ (29) and a copy of the Persian version of the Baecke questionnaire. Participants were asked to read the questionnaires and answer the questions attentively.

IPAQ is a valid and reliable questionnaire in measurement of physical activities (29, 31-33). In the current study, we used the long interview-administered version of the IPAQ. This questionnaire includes two questions on the time spent while sitting and covers four domains of the subject's physical activities: occupation (7 items), transportation ( 6 items), household/gardening ( 6 items), and leisure-time ( 6 items). The validity and reliability of the IPAQ have already been investigated in Persian language and it is an acceptable tool in assessing physical activities (29).

\subsection{Reliability Assessment}

In order to evaluate test-retest reliability, the Persian version of the Baecke was re-administered to a sample of
32 subjects randomly selected from the primary pool, 3 - 7 days after the first session.

All the subjects signed an informed consent form approved by the ethics committee of Shahid Beheshti University of Medical Sciences, Tehran, Iran.

\subsection{Statistical Analysis}

Statistical analysis of the study was performed using SPSS, version 21. Mean values of age, body mass index (BMI), weight, and height were calculated for men and women, separately. To determine possible gender differences, t-test was run.

Also, Pearson correlation coefficient was computed to compare Baecke and IPAQ scores so as to examine the validity of the Baecke questionnaire. Moreover, the intraclass correlation coefficient was used to determine test-retest reliability. We also used Cronbach's Alpha coefficient to calculate internal consistency. Alpha coefficient of 0.7 or more is acceptable. 


\section{Results}

\subsection{Subjects' Characteristics}

The mean values for age were $25.16 \pm 4.9$ and $25.9 \pm 5.8$ for men and women, respectively. Approximately $71 \%$ of males and $88 \%$ of females had academic education. Male subjects were observed to have higher weight and height values compared with those of their female counterparts; the differences were statistically significant $(\mathrm{P}<0.05)$. Subjects' characteristics are presented in Table 1.

\subsection{Reliability}

As shown in Table 2, the Persian version of Baecke questionnaire enjoys sound reliability indices in test-retest measurements (ICC > 0.7). Accordingly, the reliability indices of ICC for work, sport, leisure, and total score were $0.95,0.93,0.77$, and 0.88 , respectively. The results also demonstrated that the questionnaire has acceptable internal consistency (Cronbach's Alpha coefficient>0.7).

Validity: Findings revealed a fair positive correlation between total Baecke score and score IPAQ without the score for sitting position (Table 3$)(\mathrm{r}=0.36, \mathrm{P}=0.00)$. The correlation between total Baecke score and IPAQ score, including sitting score, was observed to be weak positive, too $(\mathrm{r}=0.19, \mathrm{P}=0.03$ ). However, no significant correlation was found between any subscale of the Baecke questionnaire and IPAQ(P> 0.05). Figure1 shows the correlation between total Baecke score and IPAQ score, without the sitting score and Figure 2 presents the correlation between total Baecke score and IPAQ score with the sitting score.

Table 2. Results of ICC for Baecke Questionnaire Subscales and Total Score ${ }^{\mathrm{a}}$

\begin{tabular}{lccc}
\hline Variables & $\begin{array}{c}\text { First } \\
\text { Measurement } \\
\mathbf{N = 3 2}\end{array}$ & $\begin{array}{c}\text { Second } \\
\text { Measurement } \\
\mathbf{N = 3 2}\end{array}$ & $\begin{array}{c}\text { ICC }(95 \% \\
\text { Confidence } \\
\text { Interval })\end{array}$ \\
\hline Work score & $2.91(0.99)$ & $2.92(0.95)$ & $0.95(0.90-0.97)$ \\
\hline Sport score & $1.43(0.57)$ & $1.46(0.54)$ & $0.93(0.86-0.96)$ \\
\hline Leisure score & $1.17(0.21)$ & $1.2(0.26)$ & $0.77(0.58-0.88)$ \\
\hline Total score & $8.14(1.41)$ & $8.26(1.33)$ & $0.88(0.76-0.94)$ \\
\hline
\end{tabular}

Abbreviations: ICC, intraclass correlation coefficient; SD, standard deviation.

${ }^{\mathrm{a}}$ Values are expressed as mean $\pm \mathrm{SD}$.

\section{Discussion}

As the results of the present study showed, the Persian version of the Baecke habitual physical activities questionnaire is a reliable and poor valid instrument for measurement of physical activities in healthy adult Persian individuals.

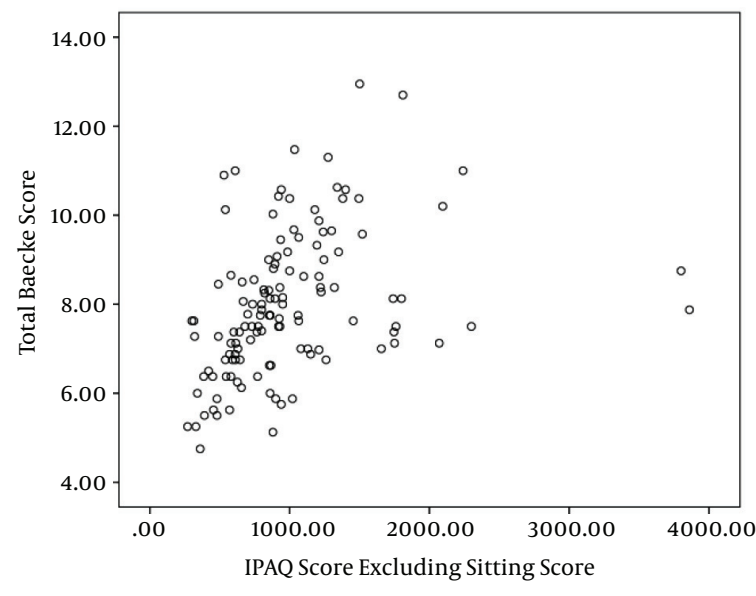

Figure 1. Correlation Between Baecke Score and IPAQ Without Sitting Score

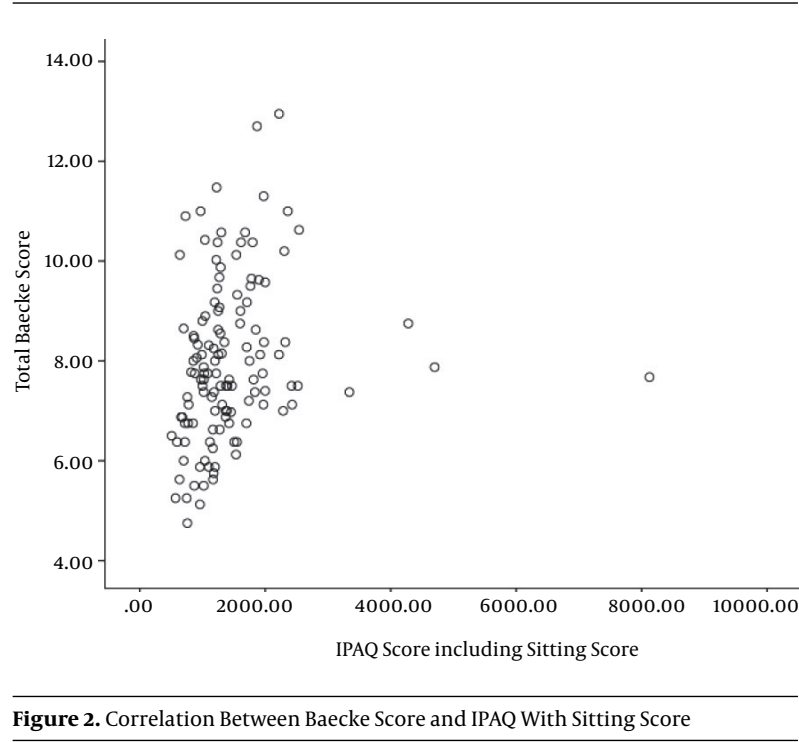

The test-retest reliability of the Baecke questionnaire has already been investigated in different populations speaking different languages $(10,13,21,26,27)$ and it was reported that the Baecke questionnaire had acceptable ICC values suggesting it as a reliable instrument. For example, the values of ICC for this questionnaire in Japanese, Flemish, and Dutch subjects were reported to be above 0.7 (10, $13,27)$. Ono et al. reported that the values of ICC in Japanese patients with hip disorder ranged between 0.78 and 0.87 (10). Studying 90 Flemish male subjects, Philippaerts et al. showed that the ICC values ranged were from 0.86 to 0.95 (27). In addition, the reliability of this questionnaire was reported to be acceptable in a study carried out on Dutch subjects (13). 
Table 3. Correlation Between Baecke Questionnaire and International Physical Activity Questionnaire

\begin{tabular}{|c|c|c|c|c|}
\hline \multirow[t]{2}{*}{ Variable } & \multicolumn{2}{|c|}{ IPAQ Score Including Siting } & \multicolumn{2}{|c|}{ IPAQ Score Excluding Sitting } \\
\hline & PValue & $\mathbf{r}$ & PValue & $\mathbf{r}$ \\
\hline Total Baecke score & $0.03^{\mathrm{a}}$ & 0.19 & $0.00^{\mathrm{a}}$ & 0.36 \\
\hline Work score & 0.69 & 0.03 & 0.34 & 0.09 \\
\hline Sport score & 0.9 & 0.01 & 0.52 & 0.01 \\
\hline Leisure score & 0.66 & 0.04 & 0.67 & 0.04 \\
\hline
\end{tabular}

Abbreviations: IPAQ, international physical activity questionnaire; r, pearson rank correlation coefficient.

${ }^{\mathrm{a}}$ Significant $\mathrm{P}$ value.

The values of ICC in our study were calculated to be between 0.77 - 0.95. Therefore, the results of the test-retest reliability are consistent with those obtained for this questionnaire in other languages such as Japanese, Flemish, and Dutch $(10,13,27)$. Although in a pilot study performed by Tilaki et al. Cronbach's $\alpha$ coefficient value of the BHPAQ was reported to be $>0.85$ for a group of healthy Iranian subjects (34), to date, literature witnesses no study reporting ICC values for the questionnaire. The results of the present study suggest that, as was demonstrated in the previous research, the Persian version of the Baecke questionnaire is reliable for measuring the physical activities in healthy Persian speaking subjects.

We used IPAQ for assessing the validity of the Persian version of Baecke questionnaire. Validity assessment of a questionnaire can be performed via direct and indirect methods. In the direct method, the correlation between the scores obtained from a questionnaire and those obtained from measurement of physical activities that are recorded by an instrument, such as pedometer and accelerometer, is calculated $(35,36)$. In the indirect method, correlation is calculated between scores obtained from a specific questionnaire and those obtained from a valid questionnaire $(7,10)$. The indirect assessment of physical activities is easier to use, less expensive, and timesaving (7). As for the present study, IPAQ was chosen as a valid questionnaire to test the validity of the Persian version of Baecke questionnaire.

As stated by Vasheghani-Farahani et al., the Persian version of IPAQ is a valid and reliable tool to determine the level of physical activities in Persian speakers, though they reported a weak positive correlation observed between physical activities and aerobic fitness (29). Also, the validity of this questionnaire was reported poor to fair in Tran et al. (31), acceptable in Vanhelst et al. (32), and moderate in Hansen et al. (33).

The results of our study revealed that physical activity scores obtained from the BHPA have a poor positive correlation with those obtained from the IPAQ. Consistent with this finding, Ono and colleagues reported that, in a group of patients with unilateral and bilateral hip disorder, the correlation between total score of the Baecke questionnaire and the step counts measured by pedometer was $0.49(10)$.

In addition, Florindo et al. asserted that the Baecke questionnaire is a valid instrument for the evaluation of habitual physical activity among people with HIV/AIDS (21). The results of their study suggested that sport score of Baecke questionnaire had a correlation with peak oxygen uptake $(r=0.41)$ and also with peak workload $(r=0.43)$. Besides, the occupational score of the Baecke questionnaire had a correlation with energy expenditure $(r=0.64)$. Nevertheless, in the cited study, no correlation was observed between the total score of the Baecke questionnaire and oxygen uptake, energy expenditure diary, and peak workload.

Furthermore, the validity of Baecke questionnaire was evaluated using the doubly labeled water method in the study by Hertogh et al. (26). In this study, the Spearman correlation coefficient between the physical activity scores obtained with doubly labeled water method and the modified Baecke questionnaire scores was reported to be 0.54 , in a population of elderly women and men (95\% CI 0.22 $0.66)$.

The correlations between HPAQ and other methods of physical activities measurement are reported in the literature to be poor to moderate. Findings of the present study, too, demonstrate similar results. The weak correlation between Baecke questionnaire and IPAQ may be partly due to the low correlation range between this questionnaire and the tools for measuring the level of physical activities. Hence, we believe that BHPAQ is a valid instrument that can be employed to measure the physical activities of healthy Persian individuals.

The current study was conducted on a limited population of adults. It is recommended that the reliability and validity of the Persian version of Baecke questionnaire be investigated with other age groups. Also, only healthy sub- 
jects were included in the current study, thus further research is necessary to examine the reliability and validity of the questionnaire in the patient groups, as well. For examining the validity of the questionnaire, an indirect method was employed in the current study; testing the validity of the instrument this time following direct methods can add to the current knowledge.

Based on the findings, it can be concluded that the Persian version of the Baecke questionnaire, with its three subscales, has an acceptable level of reliability and validity for measurement of physical activities in healthy adult Persian-speaking individuals.

\section{Acknowledgments}

The authors would like to appreciate Shahid Beheshti University of Medical Sciences, Tehran, Iran, for supporting the present project.

\section{Footnote}

Authors' Contribution: Study concept and design: Meissam Sadeghisani; data interpretation: Farideh Dehghan Manshadi; Drafting and revisions: Hadi Azimi; Study design: Ali Montazeri.

\section{References}

1. Warburton DE, Nicol CW, Bredin SS. Health benefits of physical activity: the evidence. CMAJ. 2006;174(6):801-9. doi: 10.1503/cmaj.051351. [PubMed: 16534088].

2. Macera CA, Hootman JM, Sniezek JE. Major public health benefits of physical activity. Arthritis Rheum. 2003;49(1):122-8. doi: 10.1002/art.10907. [PubMed: 12579603].

3. Warburton DE, Gledhill N, Quinney A. Musculoskeletal fitness and health. Can J Appl Physiol. 2001;26(2):217-37. [PubMed: 11312417].

4. Holmes MD, Chen WY, Feskanich D, Kroenke CH, Colditz GA. Physical activity and survival after breast cancer diagnosis. JAMA. 2005;293(20):2479-86. doi: 10.1001/jama.293.20.2479. [PubMed: 15914748].

5. Greenway KG, Walkley JW, Rich PA. Relationships between selfreported lifetime physical activity, estimates of current physical fitness, and aBMD in adult premenopausal women. Arch Osteoporos. 2015;10:34. doi: 10.1007/s11657-015-0239-y. [PubMed: 26424470].

6. Haskell WL. Physical activity by self-report: a brief history and future issues. J Phys Act Health. 2012;9 Suppl 1:S5-10. [PubMed: 22287448].

7. Negahban H, Hessam M, Tabatabaei S, Salehi R, Sohani SM, Mehravar M. Reliability and validity of the Persian lower extremity functional scale (LEFS) in a heterogeneous sample of outpatients with lower limb musculoskeletal disorders. Disabil Rehabil. 2014;36(1):10-5. doi: 10.3109/09638288.2013.775361. [PubMed: 23530691].

8. Paffenbarger RJ, Blair SN, Lee IM, Hyde RT. Measurement of physical activity to assess health effects in free-living populations. Med Sci Sports Exerc. 1993;25(1):60-70. [PubMed: 8423758].

9. Beaton DE, Bombardier C, Guillemin F, Ferraz MB. Guidelines for the process of cross-cultural adaptation of self-report measures. Spine (Phila Pa 1976). 2000;25(24):3186-91. [PubMed: 11124735]
10. Ono R, Hirata S, Yamada M, Nishiyama T, Kurosaka M, Tamura Y. Reliability and validity of the Baecke physical activity questionnaire in adult women with hip disorders. BMC Musculoskelet Disord. 2007;8:61. doi: 10.1186/1471-2474-8-61. [PubMed: 17610746].

11. Negahban H, Mostafaee N, Sohani SM, Mazaheri M, Goharpey S, Salavati M, et al. Reliability and validity of the Tegner and Marx activity rating scales in Iranian patients with anterior cruciate ligament injury. Disabil Rehabil. 2011;33(23-24):2305-10. doi: 10.3109/09638288.2011.570409. [PubMed: 21491968].

12. Adams EJ, Goad M, Sahlqvist S, Bull FC, Cooper AR, Ogilvie D, et al. Reliability and validity of the transport and physical activity questionnaire (TPAQ) for assessing physical activity behaviour. PLoS One. 2014;9(9):eee107039. doi: 10.1371/journal.pone.0107039. [PubMed: 25215510].

13. Baecke JA, Burema J, Frijters JE. A short questionnaire for the measurement of habitual physical activity in epidemiological studies. Am J Clin Nutr. 1982;36(5):936-42. [PubMed: 7137077].

14. Jancey J, Tye M, McGann S, Blackford K, Lee AH. Application of the Occupational Sitting and Physical Activity Questionnaire (OSPAQ) to office based workers. BMC Public Health. 2014;14:762. doi: 10.1186/1471-245814-762. [PubMed: 25069528].

15. Hong TK, Trang NH, van der Ploeg HP, Hardy LL, Dibley MJ. Validity and reliability of a physical activity questionnaire for Vietnamese adolescents. Int J Behav Nutr Phys Act. 2012;9:93. doi: 10.1186/1479-5868-9-93. [PubMed: 22853177].

16. Svege I, Kolle E, Risberg MA. Reliability and validity of the Physical Activity Scale for the Elderly (PASE) in patients with hip osteoarthritis. BMC Musculoskelet Disord. 2012;13:26. doi: 10.1186/1471-2474-13-26. [PubMed: 22353558].

17. Gombatto SP, Collins DR, Sahrmann SA, Engsberg JR, Van Dillen LR. Gender differences in pattern of hip and lumbopelvic rotation in people with low back pain. Clin Biomech (Bristol, Avon). 2006;21(3):263-71. doi: 10.1016/j.clinbiomech.2005.11.002. [PubMed: 16376467].

18. Scholtes SA, Gombatto SP, Van Dillen LR. Differences in lumbopelvic motion between people with and people without low back pain during two lower limb movement tests. Clin Biomech (Bristol, Avon). 2009;24(1):7-12. doi: 10.1016/j.clinbiomech.2008.09.008. [PubMed 18990474].

19. Van Dillen LR, Gombatto SP, Collins DR, Engsberg JR, Sahrmann SA Symmetry of timing of hip and lumbopelvic rotation motion in 2 different subgroups of people with low back pain. Arch Phys Med Rehabil. 2007;88(3):351-60. doi: 10.1016/j.apmr.2006.12.021. [PubMed: 17321829].

20. Carlson AR, Smith MA, McCarthy MS. Diet, physical activity, and bone density in soldiers before and after deployment. US Army Med Dep J. 2013:25-30. [PubMed: 23584905].

21. Florindo AA, Latorre Mdo R, Santos EC, Negrao CE, Azevedo LF, Segurado AA. Validity and reliability of the Baecke questionnaire for the evaluation of habitual physical activity among people living with HIV/AIDS. Cad Saude Publica. 2006;22(3):535-41. [PubMed: 16583097].

22. Autenrieth CS, Evenson KR, Yatsuya H, Shahar E, Baggett C, Rosamond WD. Association between physical activity and risk of stroke subtypes: the atherosclerosis risk in communities study. Neuroepidemiology. 2013;40(2):109-16. doi: 10.1159/000342151. [PubMed: 23095721].

23. Baecke JA, van Staveren WA, Burema J. Food consumption, habitual physical activity, and body fatness in young Dutch adults. Am J Clin Nutr. 1983;37(2):278-86. [PubMed: 6823890].

24. Buchheit M, Simon C, Charloux A, Doutreleau S, Piquard F, Brandenberger $\mathrm{G}$. Heart rate variability and intensity of habitual physical activity in middle-aged persons. Med Sci Sports Exerc. 2005;37(9):1530-4. [PubMed: 16177605].

25. Currie I, Ramsbottom R, Ludlow H, Nevill A, Gilder M. Cardiorespiratory fitness, habitual physical activity and serum brain derived neurotrophic factor (BDNF) in men and women. Neurosci Lett. 2009;451(2):152-5. doi: 10.1016/j.neulet.2008.12.043. [PubMed: 19133315]. 
26. Hertogh EM, Monninkhof EM, Schouten EG, Peeters PH, Schuit AJ. Validity of the modified Baecke questionnaire: comparison with energy expenditure according to the doubly labeled water method. Int J Behav Nutr Phys Act. 2008;5:30. doi: 10.1186/1479-5868-5-30. [PubMed: 18505554].

27. Philippaerts RM, Lefevre J. Reliability and validity of three physical activity questionnaires in Flemish males. Am J Epidemiol. 1998;147(10):982-90. [PubMed: 9596477].

28. Momenan AA, Delshad M, Sarbazi N, Rezaei Ghaleh N, Ghanbarian A, Azizi F. Reliability and validity of the Modifiable Activity Questionnaire (MAQ) in an Iranian urban adult population. Arch Iran Med. 2012;15(5):279-82. [PubMed: 22519376].

29. Vasheghani-Farahani A, Tahmasbi M, Asheri H, Ashraf H, Nedjat S, Kordi R. The Persian, last 7-day, long form of the International Physical Activity Questionnaire: translation and validation study. Asian J Sports Med. 2011;2(2):106-16. [PubMed: 22375226].

30. Bullinger M, Alonso J, Apolone G, Leplege A, Sullivan M, WoodDauphinee $S$, et al. Translating health status questionnaires and evaluating their quality: the IQOLA Project approach. International Quality of Life Assessment. J Clin Epidemiol. 1998;51(11):913-23. [PubMed: 9817108].

31. Tran DV, Lee AH, Au TB, Nguyen CT, Hoang DV. Reliability and validity of the International Physical Activity Questionnaire-Short Form for older adults in Vietnam. Health Promot J Austr. 2013;24(2):126-31. doi:
10.1071/HE13012. [PubMed: 24168739].

32. Vanhelst J, Mikulovic J, Fardy PS, Bui-Xuan G, Beghin L. Concurrent validity of the modified International Physical Activity Questionnaire for French obese adolescents. Percept Mot Skills. 2013;116(1):123-31. doi: 10.2466/03.06.PMS.116.1.123-131. [PubMed: 23829140].

33. Hansen AW, Dahl-Petersen I, Helge JW, Brage S, Gronbaek M, Flensborg-Madsen T. Validation of an Internet-based long version of the International Physical Activity Questionnaire in Danish adults using combined accelerometry and heart rate monitoring. J Phys Act Health. 2014;11(3):654-64. doi: 10.1123/jpah.2012-0040. [PubMed: 23416716].

34. Hajian-Tilaki K, Heidari B. Prevalences of overweight and obesity and their association with physical activity pattern among Iranian adolescents aged 12-17 years. Public Health Nutr. 2012;15(12):2246-52. doi: 10.1017/S1368980012001048. [PubMed: 22578771].

35. Sitthipornvorakul E, Janwantanakul P, van der Beek AJ. Correlation between pedometer and the Global Physical Activity Questionnaire on physical activity measurement in office workers. BMC Res Notes. 2014;7:280. doi: 10.1186/1756-0500-7-280. [PubMed: 24886593].

36. Hassett L, Moseley A, Harmer A, van der Ploeg HP. The reliability, validity, and feasibility of physical activity measurement in adults with traumatic brain injury: an observational study.J Head Trauma Rehabil. 2015;30(2):E55-61. doi: 10.1097/HTR.0000000000000047. [PubMed: 24721810] 